\title{
35. A MOLECULAR STRATIGRAPHIC STUDY OF PERU MARGIN SEDIMENTS, HOLE 686B, LEG 112 1
}

\author{
P. Farrimond, ${ }^{2,3}$ J. G. Poynter, ${ }^{2}$ and G. Eglinton ${ }^{2}$
}

\begin{abstract}
A molecular stratigraphic approach is applied to a suite of sediment samples from Hole 686B in the Peru upwelling area to address past changes in sea-surface temperatures, biomass composition, marine productivity, and the supply of terrestrial organic matter. A complex history of sea-surface temperatures is revealed in the alkenone unsaturation index $\left(\mathrm{U}_{37}^{\mathrm{k}}\right)$, particularly over the last $350,000 \mathrm{yr}$, probably reflecting increased intensity of coastal upwelling above this site. Changes in the relative contributions from marine and terrestrial sources of organic matter throughout the sediment sequence are revealed and discussed.
\end{abstract}

\section{INTRODUCTION}

The application of organic geochemistry to characterize sedimentary sequences on a "layer-by-layer"' basis has been called "molecular stratigraphy"' (e.g., Brassell et al., 1986b). This approach uses specific organic compounds present in sediments that are still recognizable as having a distinct biological origin even when they have undergone systematic modification during diagenesis. Such compounds are called "biological markers," or simply "biomarkers" (Eglinton and Calvin, 1967; Speers and Whitehead, 1969; Philp, 1985). Molecular parameters consisting typically of biomarker abundances or multicompound indexes are monitored within a sedimentary sequence and used to infer fluctuations in biological productivity and the supply of organic matter and changes in climate (Brassell et al., 1986a, 1986b; Poynter et al., in press, $\mathrm{a}$ and $\mathrm{b})$.

\section{Reconstruction of Past Sea-Surface Temperatures}

In the last few years, scientists have discovered that a series of long-chain alkenones, which are widespread in Quaternary marine sediments (Marlowe et al., 1984a), preserves a record of past sea-surface temperature (Marlowe, 1984; Brassell et al., 1986a, 1986b). These compounds, which are derived from prymnesiophyte algae such as Emiliania huxleyi (Volkman et al., 1980; Marlowe et al., 1984a, 1984b), display different degrees of unsaturation in sediments underlying different surface-water temperatures (Eglinton et al., 1983). A series of laboratory culture experiments demonstrated a relationship between the ratio of di- and tri-unsaturated alkenones and the growth temperature of the algae (Marlowe, 1984; Brassell et al., 1986b; Prahl and Wakeham, 1987). A molecular parameter ( $U_{37}^{k}$ Index) was developed (Brassell et al., 1986b) to record this effect:

$$
\mathrm{U}_{37}^{\mathrm{k}}=[\mathrm{C} 37: 2-\mathrm{C} 37: 4] /[\mathrm{C} 37: 2+\mathrm{C} 37: 3+\mathrm{C} 37: 4]
$$

\footnotetext{
${ }^{1}$ Suess, E., von Huene, R., et al., 1990. Proc. ODP, Sci. Results, 112: College Station, TX (Ocean Drilling Program).

2 Organic Geochemistry Unit, University of Bristol, School of Chemistry, Cantock's Close, Bristol BS8 1TS, United Kingdom.

${ }^{3}$ Organic Geochemistry Unit, University of Newcastle upon Tyne, Department of Geology, Drummond Building, Newcastle upon Tyne NE1 7RU, United Kingdom.
}

where $\mathrm{C} 37: 2, \mathrm{C} 37: 3$, and $\mathrm{C} 37: 4$ denote the di-, tri, and tetra-unsaturated $\mathrm{C}_{37}$ alkenones, respectively. However, the tetra-unsaturated compound is only biosynthesized in cold conditions; thus, for most marine sediments this equation simplifies to:

$$
\mathbf{U}_{37}^{k}=[\mathrm{C} 37: 2] /[\mathrm{C} 37: 2+\mathrm{C} 37: 3] .
$$

Investigations of fluctuations in $U_{37}^{k}$ index with depth in Quaternary marine sediment sequences typically reveal striking similarity to the oxygen isotope record of planktonic foraminifers (Brassell et al., 1986b; Poynter et al., in press, a). Such observations, together with the results from laboratory culture experiments, formed the basis for Brassell et al.'s conclusion (1986b) that changes in past sea-surface water temperatures could be recognized from the stratigraphic record of $U_{37}^{k}$ values in marine sediments. Unlike the oxygen isotope method, which monitors both local water temperature and global ice volume (Dansgaard and Tauber, 1969), the $U_{37}^{k}$ approach seems to be a measure of local sea-surface temperature only (Yendle, 1989). As such, the organic geochemical method records temperature changes resulting from both glacial/interglacial climatic change and local upwelling intensity. Farrington et al. (1988) successfully applied the $U_{37}^{k}$ approach to document temperature changes associated with El Niño events in the Peru upwelling area over the last $130 \mathrm{yr}$.

\section{This Study}

In this study we apply the molecular stratigraphic approach to a suite of 84 sediment samples from the upper $160 \mathrm{~m}$ of Hole $686 \mathrm{~B}$ to infer past fluctuations in sea-surface temperature, marine productivity, and the supply of terrestrial organic matter. The molecular parameters used include the $U_{37}^{k} I n d e x$, and the abundances of various compounds of well-characterized biological origins (summarized in Table 1; see Farrimond et al., this volume, for a full discussion of the biological sources of sedimentary lipids in the Peru upwelling area).

Site 686 lies in a water depth of approximately $450 \mathrm{~m}$ in the Pisco Basin on the Peru margin. Drilling at Hole 686B penetrated a thick Quaternary sediment sequence deposited at an estimated average sedimentation rate of 15 to $20 \mathrm{~cm} / \mathrm{k}$.y. in the upper part (Suess, von Huene, et al., 1988; Wefer et al., this volume). This site was originally selected for detailed molecular stratigraphy in the belief that it would provide an expanded and continuous record of sedimentation on the Peru margin. However, subsequent shore-based studies have illus- 
Table 1. Summary of the inferred biological sources of sedimentary lipids used in the molecular stratigraphy of Hole 686B.

\begin{tabular}{|c|c|}
\hline $\begin{array}{l}\text { Compound or } \\
\text { compound type }\end{array}$ & $\begin{array}{c}\text { Inferred } \\
\text { biological origin }^{\mathrm{a}}\end{array}$ \\
\hline Long-chain alkenones & Prymnesiophyte algae \\
\hline Alkanediols & Cyanobacteria? (marine) \\
\hline "Unknown compound" & (Marine) \\
\hline Dinosterol & Dinoflagellates \\
\hline Long-chain n-alkanes & Terrestrial higher plants \\
\hline Long-chain n-alkanols & Terrestrial higher plants \\
\hline
\end{tabular}

trated the true complexity of the chronostratigraphy (Wefer et al., this volume). Carbonate dissolution has had a marked effect on the foraminifers in the sediments, precluding the use of oxygen isotope stratigraphy in the upper $56 \mathrm{~m}$ of Hole 686B. As a result, the chronostratigraphy is based, in part, upon organic-carbon contents and sediment texture and must be considered tenuous. Using these observations, Wefer et al. (this volume) arrive at a mean sedimentation rate of 15 $\mathrm{cm} / \mathrm{k} . \mathrm{y}$. in the upper $105 \mathrm{~m}$. A prominent hiatus is evident between 105 and 120 meters below seafloor (mbsf), beneath which the sedimentation rate is estimated as about $100 \mathrm{~cm} /$ k.y. Obviously, these problems of time-stratigraphic control at Site 686 will make the molecular stratigraphic data presented here difficult to interpret fully.

\section{EXPERIMENTAL METHODS}

Sediment samples were extracted ultrasonically in organic solvents to yield a total organic extract, which was analyzed by gas chromatography after derivatization. Complete details of the work-up and analysis procedures are given in Farrimond et al. (this volume).

Abundances of individual compounds were calculated by comparing their peak areas with those of internal standards, as measured using a VG Minichrom data system. Peak area data were transferred to a Lotus 123 spreadsheet for manipulation and plotting. Principal components analysis (PCA) was performed using a program written with Turbo Pascal v3.02A and run under MS-DOS 3.2 (Yendle, 1989).

PCA is used to reduce the data set comprising the abundances of individual compounds of each sediment sample. This approach identifies dimensions of maximum variation in the original multidimensional data space; these are defined in terms of vectors that are linear combinations of the original variables. The multipliers of these variables are the principal component loadings. The original data set can be represented as coordinates (scores) on the principal component vectors, thus providing a low-dimensional (usually two-dimensional) representation summarizing the bulk of the variance in the data set. A further advantage of PCA is that the approach reveals correlations between variables that may not be apparent from the original data set.

\section{RESULTS AND DISCUSSION}

\section{$\mathrm{U}_{\mathbf{3 7}}^{\mathbf{k}}$ Index and Sea-Surface Temperatures}

The $U_{37}^{k}$ record for Hole $686 \mathrm{~B}$ is complex (Fig.1), and we interpret this record as documenting many rapid and intense fluctuations in sea-surface temperature. This curve apparently shows considerably more complexity than a major $100,000-y r$ glacial/interglacial climatic cycle (commonly observed in

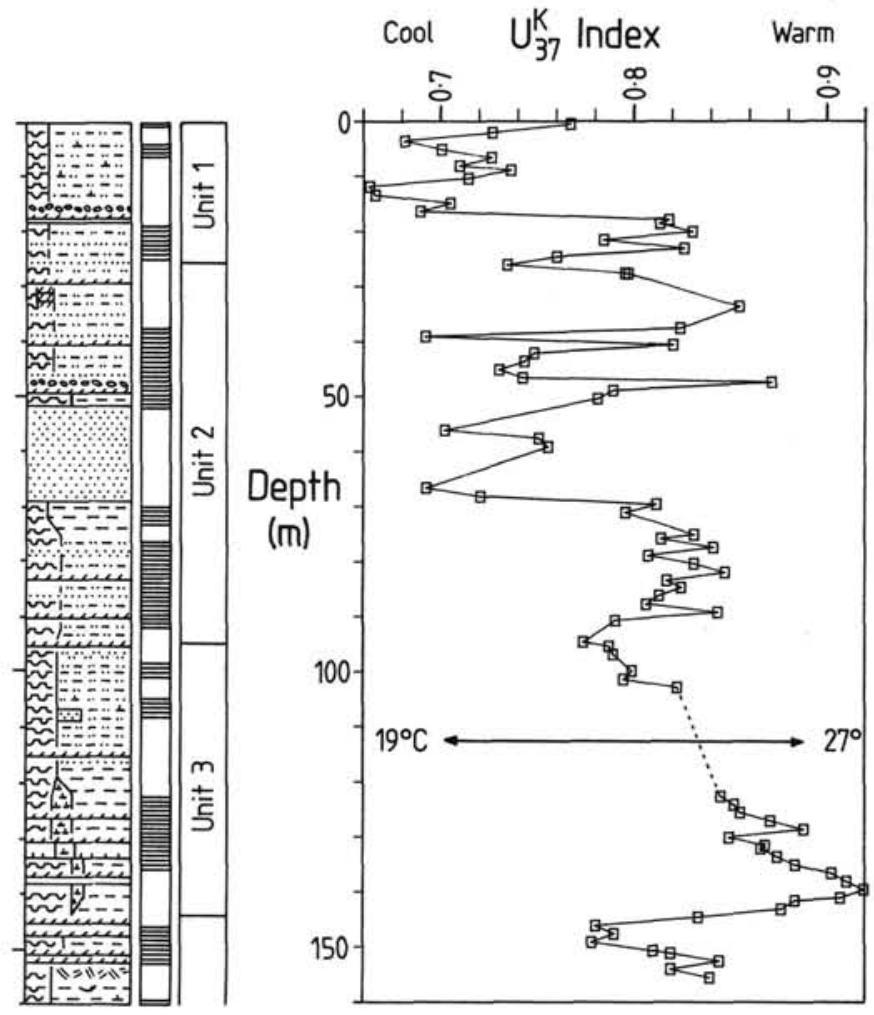

Figure 1. A downhole plot of $\mathrm{U}_{37}^{\mathrm{k}}$ index in Hole $686 \mathrm{~B}\left(\mathrm{U}_{37}^{\mathrm{k}}=\right.$ $[37: 2] /[C 37: 2+37: 3])$. Approximate temperature ranges are shown, as calculated from the calibration experiments of Prahl and Wakeham (1987). The lithologic plot displayed alongside has been redrawn from Suess, von Huene, et al. (1988); predominantly laminated intervals are marked, as are the lithologic units.

other marine regions; see Brassell et al., 1986b; Poynter et al. in press, a). The upper $70 \mathrm{~m}$ of this core displays a rapidly fluctuating $U_{37}^{k}$ record that ranges between values of 0.66 and 0.88 ; these values record a range in sea-surface temperature of approximately $7^{\circ} \mathrm{C}$, according to the calibration of Prahl and Wakeham (1987). Below this depth, the $U_{37}^{k}$ record is less variable and documents an apparent temperature range of about $4^{\circ} \mathrm{C}$ (Fig.1). The average glacial to interglacial changes in sea-surface temperature in this region off Peru were estimated as approximately $3^{\circ} \mathrm{C}$, on the basis of assemblages of foraminifers (Broecker and Peng, 1982); this compares well with the estimated temperature range of $4^{\circ} \mathrm{C}$ recorded in the lower part of the $U_{37}^{k}$ record. Furthermore, this $U_{37}^{k}$ curve parallels the benthic foraminiferal oxygen isotope record (Wefer et al., this volume). However, owing to poor foraminifer preservation in the upper part of the core, oxygen isotope stratigraphy is only available below 55 mbsf. Nevertheless, in the lower part of our $U_{37}^{k}$ profile the signals co-vary, suggesting that the $U_{37}^{k}$ values in this region of the core may be truly documenting changes in sea-surface temperature in response to glacial/interglacial cyclicity.

The upper $70 \mathrm{~m}$ of the $\mathrm{U}_{37}^{\mathrm{k}}$ record is more complex (Fig.1). Here, we infer a lower average sea-surface temperature of about $21^{\circ} \mathrm{C}$, according to the $\mathrm{U}_{37}^{\mathrm{k}}$ calibration of Prahl and Wakeham (1987), and fluctuations are more intense (about $7^{\circ} \mathrm{C}$ range) and frequent. The most likely explanation for these features involves changes in the intensity of coastal upwelling of cold, nutrient-rich water above this site. The data suggest that upwelling at Site 686 became more prominent at a point near $70 \mathrm{mbsf}$ in the sedimentary record (about $450,000 \mathrm{yr}$ ago on the basis of an estimated sedimentation rate of $15 \mathrm{~cm} / \mathrm{k} . \mathrm{y}$.). 


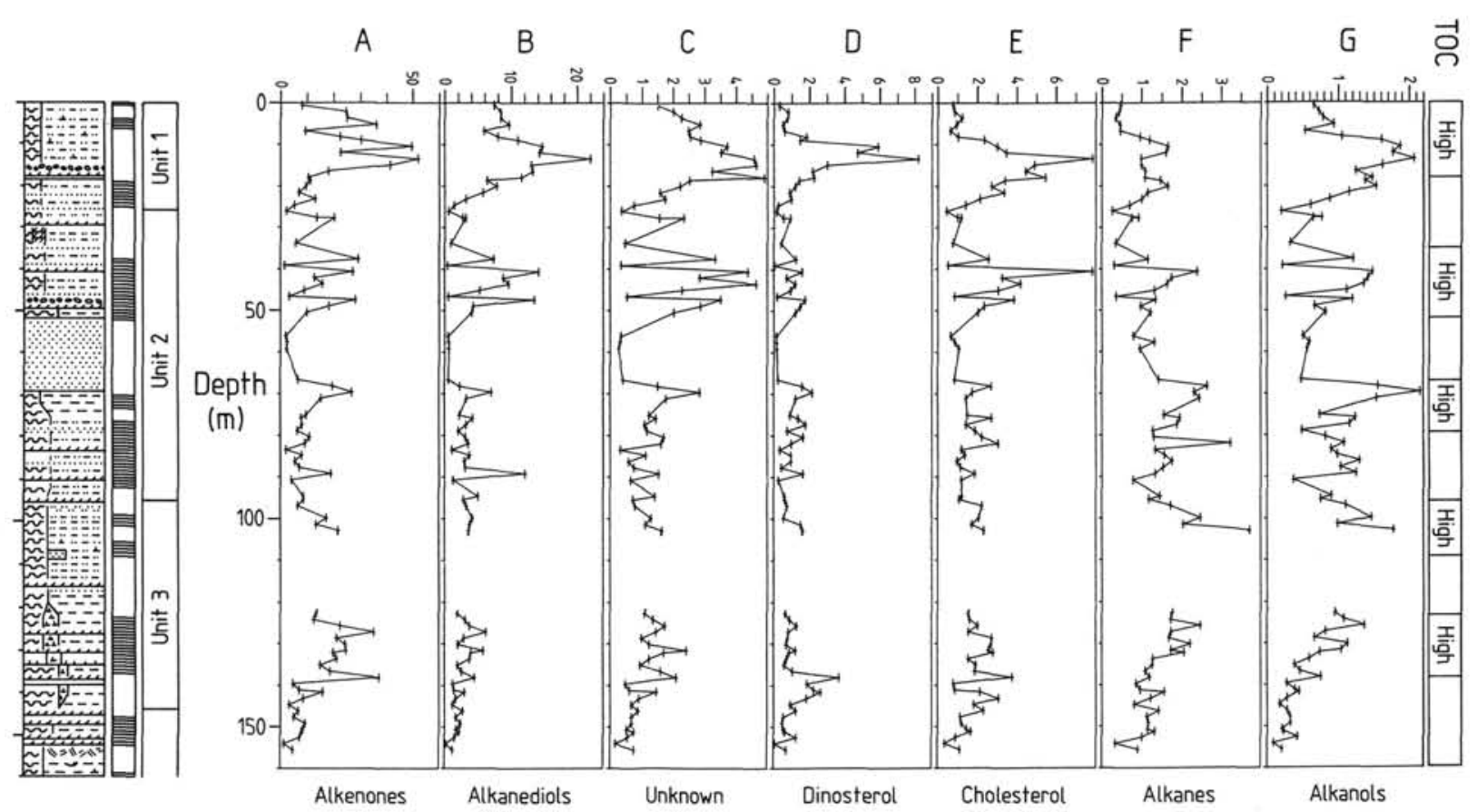

Figure 2. Downhole plots of lipid abundances (in $\mu \mathrm{g} / \mathrm{g}$ dry weight sediment) as follows: A. Sum of C37:2 and C37:3 alkenones. B. Sum of $\mathrm{C}_{30}$ and $\mathrm{C}_{32}$ alkan-1,15-diols (and co-eluting ketols). C. Unknown compound eluting after C39:2 alkenone. D. Dinosterol. E. Cholesterol + cholestanol. F. Sum of $C_{29}$ and $C_{31} n$-alkanes. G. Sum of $C_{26}$ and $C_{28} n$-alkanols. Intervals of highest average TOC content are marked alongside (data from Wefer et al., this volume).

This suggestion may be consistent with a progressive deepening of the water column in this area. Indeed, benthic foraminiferal assemblages record a change in water depth at this site from about $150 \mathrm{~m}$ (at $160 \mathrm{mbsf}$ ) to $450 \mathrm{~m}$ at the present day (Resig, this volume), owing to subsidence of the Peru continental margin. Before approximately $450,000 \mathrm{yr}$ ago (70 mbsf), this site may have lain inshore from the zone of cool surface waters that resulted from upwelling, thus leading to the preservation of a relatively warm sea-surface temperature signal in the sedimentary organic matter. Nutrient supply, however, must have been sufficiently high to produce equally organic-rich sediments both before and after $450,000 \mathrm{yr}$ ago (see total organic-carbon data of Wefer et al., this volume).

If the interpretation that periods of cool sea-surface temperatures in the upper part of the $U_{37}^{k}$ record reflect times of most intense coastal upwelling is correct, then we might expect these periods to be represented by the most organicrich sediments. This is certainly true for the uppermost $35 \mathrm{~m}$ of the core, where cooler sea-surface temperatures as low as about $18^{\circ}$ to $19^{\circ} \mathrm{C}$, according to the calibration of Prahl and Wakeham (1987), were recorded over the interval (upper 15 m) where organic-carbon contents are high (up to $5.2 \%$; average $2.5 \%$ to $3 \%$; Wefer et al., this volume). However, over the interval from 40 to $70 \mathrm{mbsf}$, there is no such correlation. Here, the situation is apparently more complex, with factors other than upwelling intensity presumably influencing preservation of organic carbon. An integration of data from various techniques will be necessary for complete interpretation of the sedimentary record.

Finally, note that bioturbation may modify the lipid signal preserved in the sedimentary sequence-effectively "smoothing" fluctuations in the signal. However, such biological mixing of the sediment acts on a scale of tens of centimeters, and the samples in this study have been typically taken from $1.5-\mathrm{m}$ intervals. Consequently, one can assume that bioturbation has not significantly influenced the lipid profiles reported here.

\section{Lipid Concentrations}

Concentrations of biological marker compounds (relative to dry sediment weight) are plotted vs. depth in the sediment sequence in Figure 2. The lipids of presumed marine derivation include alkenones, alkanediols, dinosterol, and cholesterol plus cholestanol (Table 1; see the companion paper of Farrimond et al., this volume, for a discussion of lipid sources). These lipids display comparable downhole abundance profiles, varying positively in accordance with the organic richness of the sediments (see total organic-carbon data of Wefer et al., this volume). On the basis of both molecular and bulk organic geochemical evidence, most of the sedimentary organic matter has been ascribed to a marine origin (Farrimond et al., this volume; Patience et al., this volume; ten Haven et al., this volume). Consequently, this co-variance between these lipids and organic richness is expected. The marine lipid profiles display two distinct abundance maxima, from 10 to $20 \mathrm{~m}$ and from 35 to $50 \mathrm{mbsf}$, although major fluctuations in concentration have been superimposed (Fig. 2). On average, these marine-derived components are less abundant (relative to dry weight sediment) in the lower part of the sequence; in contrast, total organic-carbon (TOC) values show no such reduction (Wefer et al., this volume). This reduction in marine lipid concentration is presumably a result of diagenesis.

Terrestrial higher-plant lipids include the n-alkanes $\left(\mathrm{C}_{29}\right.$ and $\left.\mathrm{C}_{31}\right)$ and n-alkanols $\left(\mathrm{C}_{26}\right.$ and $\left.\mathrm{C}_{28}\right)$, which make up a much smaller proportion of the TOC. Consequently, these lipids exhibit less dependence upon organic richness in their concentration profiles, although the n-alkanol signal in particular does show some similarities to the marine lipid profiles (Fig. 2 ). The n-alkanes and n-alkanols apparently co-vary, suggest- 


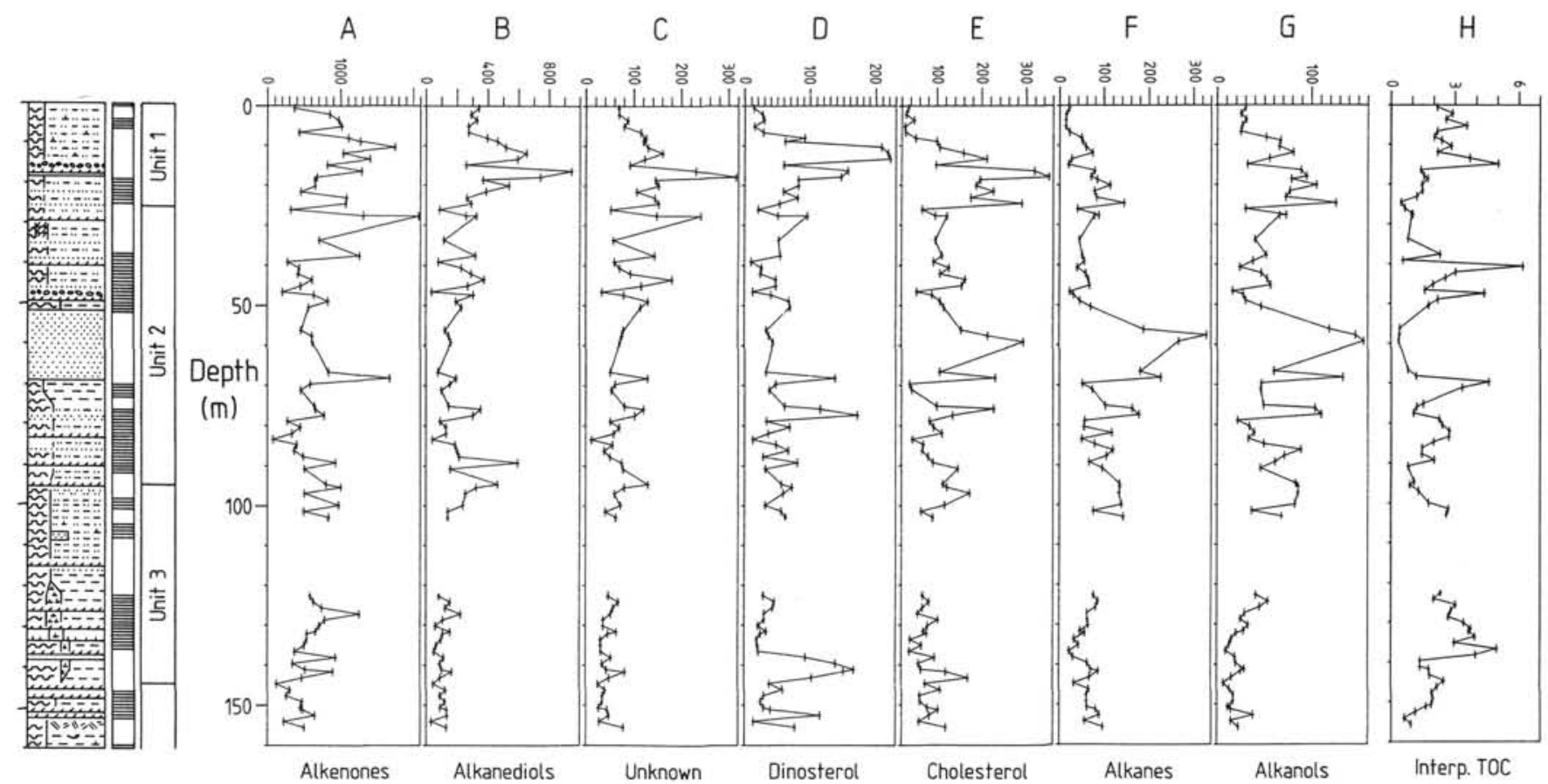

Figure 3. Downhole plots of lipid abundances normalized to interpolated organic-carbon contents (expressed as parts per million organic carbon; from the TOC data of Wefer et al., this volume). Plots are as follows: A. Sum of C37:2 and C37:3 alkenones. B. Sum of $\mathrm{C}_{30}$ and $\mathrm{C}_{32}$ alkan-1,15-diols (and co-eluting ketols). C. Unknown compound eluting after C39:2 alkenone. D. Dinosterol. E. Cholesterol + cholestanol. F. Sum of $C_{29}$ and $C_{31} n$-alkanes. G. Sum of $C_{26}$ and $C_{28}$ n-alkanols. The interpolated organic-carbon values $(H)$ are plotted alongside for reference (see Wefer et al., this volume, for the original data).

ing a common biological source (terrigenous plants) and possibly the same transport mechanism. However, superimposed upon this apparent co-variance is a depth trend whereby the n-alkanes become increasingly more abundant relative to the n-alkanols (Fig. 2). This observation presumably reflects diagenetic loss of the functionalized alkanols in favor of the more biologically resistant $n$-alkanes.

The lipid data become more meaningful when expressed relative to TOC rather than sediment weight. In the absence of measured TOC values for the precise sample intervals studied here, we interpolated the organic-carbon data of Wefer et al. (this volume) to our sample depths to arrive at estimated TOC contents. Obviously, these values will be approximate, and in some instances, misleading, as fluctuations in the organic richness of these sediments are known to occur over small depth intervals, and even between individual laminae ( $\mathrm{Pa}-$ tience et al., this volume).

\section{Lipid Abundances (Relative to TOC)}

Once the organic richness of the sediments has been nominally taken into account, variations in the actual lipid composition of the sedimentary organic matter may be addressed. The downhole "TOC-normalized" lipid abundance profiles are shown in Figure 3. The co-variance of the terrestrially derived n-alkanes and n-alkanols is immediately apparent, as already established. This land-plant contribution to the sedimentary organic matter reaches a maximum at about 55 to $70 \mathrm{mbsf}$ in lithologic Unit II, a part of the core that is particularly rich in sand. Marine lipid abundances are relatively low over this interval, with the exception of cholesterol (plus cholestanol); this observation is difficult to rationalize without more detailed investigation, particularly in the reconstruction of changes in sea level. It is possible that a change in sea level promoted high energy conditions (boundary layer) on the shelf at this time, allowing for the transportation of sand and terrestrial organic debris farther offshore.

Marine lipids (as monitored by alkenones, alkanediols, dinosterol, and cholesterol plus cholestanol) become an increasingly less significant fraction of the sedimentary organic matter with increasing depth in the sequence (Fig. 3). In general, these lipids co-vary, although their individual relative contributions are by no means constant, presumably reflecting changes in the biomass composition in the water column. Of particular note are two distinctive maxima in the abundance of dinosterol, suggesting increased dinoflagellate productivity above the site, at about $12 \mathrm{~m}$ and $140 \mathrm{mbsf}$; no other marine lipids increase substantially over this interval.

\section{Principal Components Analysis}

Owing to the complex nature of the "TOC-normalized" lipid abundance data set, principal components analysis (PCA) was used to identify co-variances and trends within the data. PCA is an objective method of combining the original variables (in this case lipid abundances) into linear combinations (principal components) which effectively describe the major patterns of variance in a data set (Sachs et al., 1977). The data set comprised 13 individual lipids as follows: $\mathrm{C}_{29}$ and $\mathrm{C}_{31}$ n-alkanes; $\mathrm{C}_{26}$ and $\mathrm{C}_{28}$ n-alkanols; dinosterol; cholesterol (+ cholestanol); $\mathrm{C}_{30}$ and $\mathrm{C}_{32}$ alkane-1,15-diols (+ alkan15-one-1-ols); $\mathrm{C} 37: 3 \mathrm{Me}, \mathrm{C} 37: 2 \mathrm{Me}$, and C39:2Et alkenones; $\mathrm{C} 37: 2 \mathrm{Me}$ alkenoate; and an unknown compound eluting after C39:2Et alkenone. The lipid abundances were normalized to interpolated organic-carbon contents, and logarithms taken, before PCA.

All 13 variables correlated positively with the first principal component (PC1), which is interpreted as indicating some residual organic-richness-related variance within the data set. In contrast, the second and third principal components ( $\mathrm{PC} 2$ 


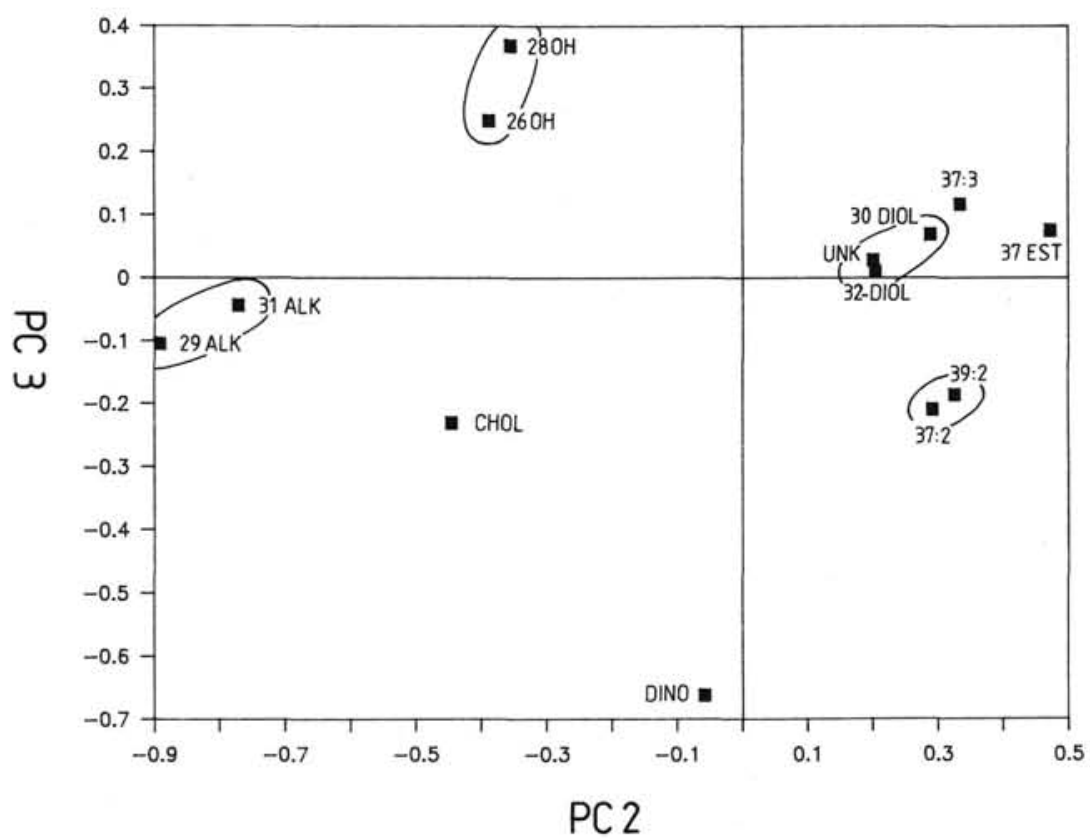

Figure 4. A correlations plot showing the relationships between the variables (TOCnormalized lipid abundances) in terms of the second and third principal components. Key: 29ALK and 31ALK $=\mathrm{C}_{29}$ and $\mathrm{C}_{31}$ n-alkanes; $260 \mathrm{H}$ and $280 \mathrm{H}=\mathrm{C}_{26}$ and $\mathrm{C}_{28}$ n-alkanols; $\mathrm{CHOL}=$ Cholesterol $(+$ cholestanol); DINO $=$ Dinosterol; 30DIOL and 32DIOL $=\mathrm{C}_{30}$ and $\mathrm{C}_{32}$ alkan-1,15-diols $(+$ co-eluting ketols); UNK $=$ Unknown compound; $37: 3=\mathrm{C}_{37}$ tri-unsaturated methyl alkenone; $37: 2=\mathrm{C}_{37}$ di-unsaturated methyl alkenone; 39:2 $=\mathrm{C}_{39}$ di-unsaturated ethyl alkenone; 37EST $=\mathrm{C}_{37}$ alkenoate. Note the close correlations between individual compounds of the same lipid class (e.g., n-alkanes, n-alkanols, alkanediols, di-unsaturated alkenones).

and PC3) describe significant variance between different lipids. A correlations plot of the variables (PC2 vs. PC3; Fig. 4) demonstrates the close co-variance of the $\mathrm{C}_{26}$ and $\mathrm{C}_{28} \mathrm{n}$ alkanols, and of the $\mathrm{C}_{29}$ and $\mathrm{C}_{31} \mathrm{n}$-alkanes, thus justifying our use of these lipid sums to represent a specific biological source in the downhole lipid abundance plots (Figs. 2 and 3). The separation between the n-alkanes and n-alkanols in the PCA (Fig. 4) is thought to be the result of the diagenetic loss of $\mathrm{n}$-alkanols, as discussed earlier.

The two di-unsaturated alkenones (37:2Me and 39:2Et) closely co-vary in terms of PC2 and PC3, but plot away from the $\mathrm{C}_{37}$ tri-unsaturated alkenone and the $\mathrm{C}_{37}$ alkenoate. This observation is expected from the knowledge of varying unsaturation $\left(\mathrm{U}_{37}^{k}\right.$ index) in the alkenones, and the variation in ester/alkenone ratio in Emiliania huxleyi depending upon growth temperature (Prahl et al., 1988). The unknown component appears to co-vary with the $\mathrm{C}_{32}$ and $\mathrm{C}_{30}$ alkan1,15-diols (Fig. 4). This apparent correlation may indicate a common biological origin for these compounds, although this cannot be assumed without further investigation. Dinosterol and cholesterol (plus co-eluting cholestanol) plot independently of each other and of the other lipids. Once the significant variance of lipid composition has been described in two principal components (PC2 and PC3), the scores on these components may be plotted downhole through the sample sequence (Fig. 5). Positive excursions of PC2 indicate prominent alkenones and alkanediols, which are marine-derived lipids from Prymnesiophyte algae and cyanobacteria, while negative PC2 scores reflect samples containing the highest amounts of n-alkanes and n-alkanols (both derived from terrestrial higher plants), and, surprisingly, cholesterol (plus cholestanol). Consequently, PC2 may be viewed as an indicator of the contribution of marine vs. terrestrial organic matter to the sediments. Dinosterol exerts little influence on PC2, but makes up a major part of the variance described by PC3 (Fig. 4). Intervals of the sediment sequence containing major proportions of dinosterol, and thus reflecting increased dinoflagellate productivity, are recorded by negative excursions in PC3 (10-14 mbsf and 139-148 mbsf; Fig. 5). It is significant that these peaks in dinoflagellate productivity both lead Prymnesiophyte productivity maxima (recorded in "marine" signal; Fig. 5). It is possible that migration of the upwelling center (caused by fluctuations in sea level) and consequent changes in nutrient chemistry have resulted in different phytoplankton dominating the water column above this site at certain times. The lipid differences preserved in the sediment sequence may be documenting such changes in biomass composition.

Marine-derived lipids from prymnesiophytes and cyanobacteria are most prominent in the upper part of the section (upper $18 \mathrm{~m}$; Fig. 5), while terrestrially derived n-alkanols and n-alkanes increase in Unit II (from $55 \mathrm{~m}$ to about 100 mbsf; Fig. 5). The interval of most significant terrestrial influence on lipid composition ( 55 to $70 \mathrm{mbsf}$ ) corresponds to the part of the core dominated by sand.

No notable cycliclty can be detected in these curves; further study must wait for a more detailed time scale.

\section{CONCLUSIONS}

The molecular stratigraphic results presented here illustrate the complexity of environmental fluctuations, in terms of biomass composition, productivity, upwelling, and preservation of organic matter, in the Peru upwelling. Despite these 


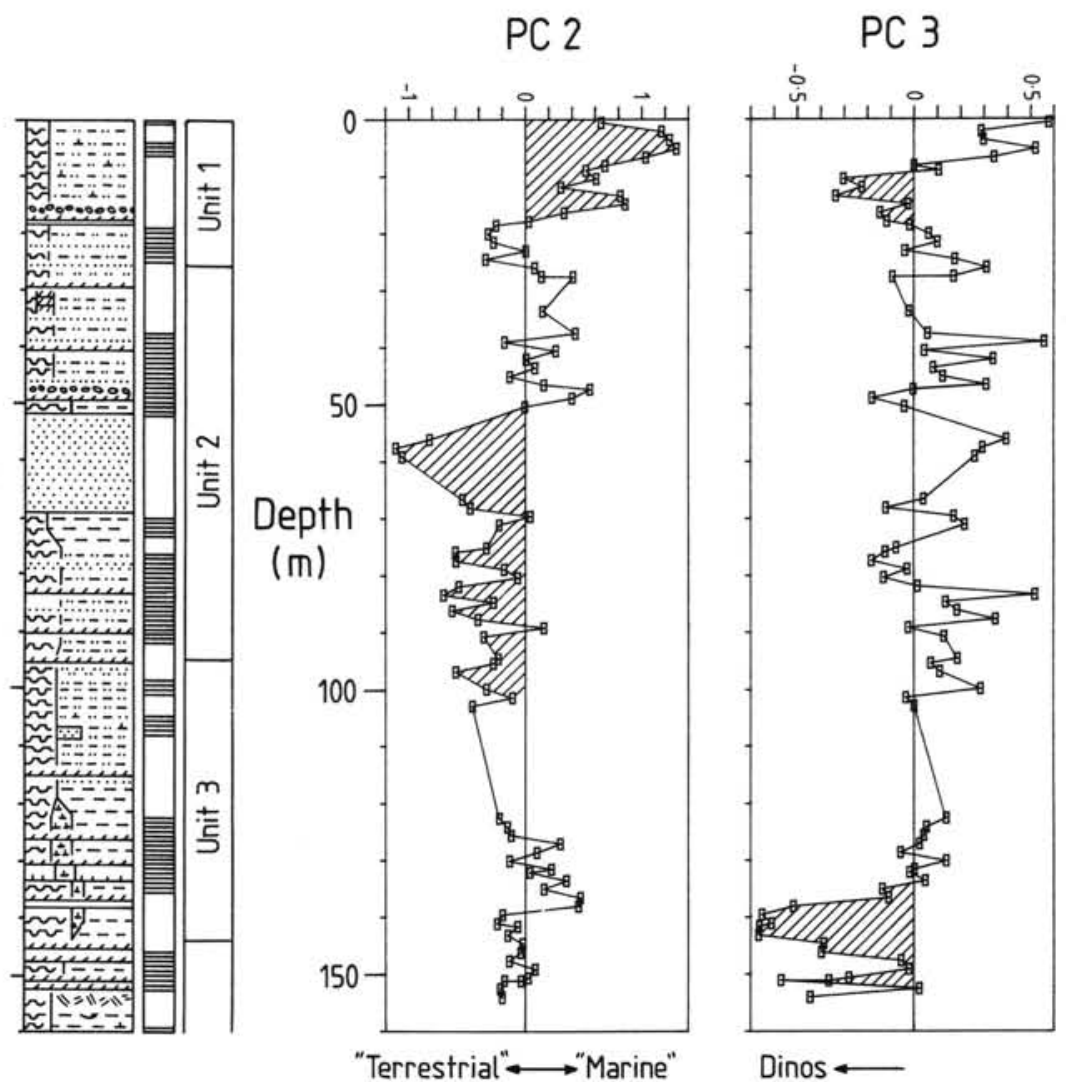

Figure 5. Downhole score plots of the second and third principal components. Fluctuations in PC2 essentially represent changes in the relative contributions of "marine" (prymnesiophyte algae and cyanobacteria; alkenones and alkanediols-see Fig. 4) and terrestrial (n-alkanes and n-alkanols-see Fig. 4) organic matter. Negative excursions in the PC3 profile record intervals of high dinosterol concentration (see Fig. 4), presumably recording periods of increased dinoflagellate productivity.

diverse interrelated factors, the following conclusions may be drawn from this study:

1. Application of the alkenone unsaturation technique reveals that this region of the Peru upwelling area has seen a complex history of sea-surface temperatures, particularly since about $450,000 \mathrm{yr}$ ago. Before this time, the site was apparently characterized by warmer surface waters; a glacial/interglacial cyclicity can be inferred in the alkenone unsaturation signal in this deeper part of the sequence.

2. Long-chain n-alkanes $\left(\mathrm{C}_{29}\right.$ and $\left.\mathrm{C}_{31}\right)$ and n-alkanols $\left(\mathrm{C}_{26}\right.$ and $\mathrm{C}_{28}$ ) co-vary, suggesting a common biological origin (terrestrial higher plants) for these lipid classes. However, a superimposed depth-related trend of decreasing n-alkanol abundance relative to $n$-alkanes was noted, both from the principal components analysis and downhole lipid abundance profiles, presumably recording preferential diagenetic loss of the functionalized alkanols.

3. Marine-derived lipids dominate the extractable sedimentary organic matter throughout the sequence, but are particularly prominent in the upper $20 \mathrm{~m}$. Application of PCA demonstrates that the contribution from terrestrially derived organic matter increases significantly within Unit II, especially in a sand-dominated interval of the sequence between 55 and 70 mbsf.

4. Application of PCA demonstrates the presence of two intervals of especially high dinosterol abundance, recording periods of increased dinoflagellate productivity in this region, possibly resulting from migration of the center of the upwelling cell.

\section{ACKNOWLEDGMENTS}

We are grateful to the Natural Environment Research Council for GC-MS facilities (GR3/2951 and GR3/3758) and for grants supporting research on molecular stratigraphy (GR3/5957 and GST/ $02 / 247$ ). We also thank P. W. Yendle for helpful discussions concerning the application of principal components analysis, E. Suess for kindly supplying organic-carbon data, and Y. Hall for typing this manuscript.

\section{REFERENCES}

Brassell, S. C., Brereton, R. G., Eglinton, G., Grimalt, J., Liebezeit, G., Marlowe, I. T., Pflaumann, U., and Sarnthein, M., 1986a. Palaeoclimatic signals recognized by chemometric treatment of molecular stratigraphic data. In Leythaueser, D., and Rullkötter, J. (Eds.), Advances in Organic Geochemistry. Org. Geochem., 10:649-660.

Brassell, S. C., Eglinton, G., Marlowe, I. T., Pflaumann, U., and Sarnthein, M., 1986b. Molecular stratigraphy: a new tool for climatic assessment. Nature, 320:129-133.

Broecker, W. S., and Peng, T.-H., 1982. Tracers in the Sea: New York (Eldigio Press), 446-451.

Dansgaard, W., and Tauber, H., 1969. Glacier oxygen-18 content and Pleistocene ocean temperatures. Science, 166:499-502.

Eglinton, G., and Calvin, M., 1967. Chemical fossils. Sci. Am., 216:32-43.

Eglinton, G., Brassell, S. C., Howell, V., and Maxwell, J. R., 1983. The role of organic geochemistry in the Deep Sea Drilling Project 
(DSDP/IPOD). In Bjor $\phi y$, M. et al. (Eds.), Advances in Organic Geochemistry 1981: Chichester (Wiley), 391-400.

Farrington, J. W., Davis, A. C., Sulanowski, J., McCaffrey, M. A., McCarthy, M., Clifford, C. H., Dickinson, P., and Volkman, J. K., 1989. Biogeochemistry of lipids in surface sediments of the Peru Upwelling Area at $15^{\circ} \mathrm{S}$. In Matavelli, L., and Novelli, L. (Eds.), Advances in Organic Geochemistry 1987. Org. Geochem., 13:607-617.

Marlowe, I. T., 1984. Lipids as palaeoclimatic indicators [Ph.D. dissert.]. Univ. of Bristol, United Kingdom.

Marlowe, I. T., Brassell, S. C., Eglinton, G., and Green, J. C., 1984a. Long-chain unsaturated ketones and esters in living algae and marine sediments. In Schenck, P. A., de Leeuw, J. W., and Lijmback, G.W.M. (Eds.), Advances in Organic Geochemistry 1983. Org. Geochem., 6:135-141.

Marlowe, I. T., Green, J. C., Neal, A. C., Brassell, S. C., Eglinton, G., and Course, P. A., 1984b. Long-chain $\left(n-C_{37}-C_{39}\right)$ alkenones in the Prymnesiophyceae. Distribution of alkenones and other lipids and their taxonomic significance. Br. Phycol. J., 19:203-216.

Philp, R. P., 1985. Biological markers in fossil fuel production. Mass Spec. Rev., 4:1-54.

Poynter, J. G., Farrimond, P., Brassell, S. C., and Eglinton, G., in press a. A molecular stratigraphic study of sediments from Holes 658A and 660A, ODP Leg 108. In Ruddiman, W., Sarnthein, M., et al., Proc. ODP. Sci. Results, 108: College Station, TX (Ocean Drilling Program).

Poynter, J. G., Farrimond, P., Robinson, N., and Eglinton, G., in press $\mathrm{b}$. Aeolian-derived higher plant lipids in the marine sedimentary record: links with paleoclimate. In Palaeoclimatology and
Palaeometeorology: Modern and Past Patterns of Global Atmospheric Transport. NATO ASI Series D.

Prahl, F. G., and Wakeham, S. G., 1987. Calibration of unsaturation patterns in long-chain ketone compositions for paleotemperature assessment. Nature, 330:367-369.

Prahl, F. G., Muehlhausen, L. A., and Zahnle, D. L., 1988. Further evaluation of long-chain alkenones as indicators of palaeoceanographic conditions. Geochim. Cosmochim. Acta, 52:2303-2310.

Sachs, M. H., Webb, T., and Clark, D. R., 1977. Paleoecological transfer functions. Annu. Rev. Earth Planet. Sci., 5:159-178.

Speers, G. C., and Whitehead, E. V., 1969. Crude Petroleum. In Eglinton, G., and Murphy, M.T.J. (Eds.), Organic Geochemistry. Methods and Results: New York-Berlin-Heidelberg (SpringerVerlag), 638-675.

Suess, E., von Huene, R., et al., 1988. Proc. ODP., Init. Repts., 112: College Station, TX (Ocean Drilling Program).

Volkman, J. K., Eglinton, G., Corner, E.D.S., and Sargent, J. R., 1980. Novel unsaturated straight-chain $C_{3} T C_{39}$ methyl and ethyl ketones in marine sediments and a coccolithophore Emiliania huxleyi. In Douglas, A. G., and Maxwell, J. R. (Eds.), Advances in Organic Geochemistry: Oxford (Pergamon Press), 219-227.

Yendle, P. W., 1989. Chemometric studies of biochemical and geochemical systems [Ph.D. dissert.]. Univ. of Bristol, United Kingdom.

Date of initial receipt: 24 October 1988

Date of acceptance: 21 August 1989

Ms 112B-150 